\title{
Pollination of Dendrobium Hybrids Using Cryopreserved Pollen
}

Wagner A. Vendrame ${ }^{1}$

Environmental Horticulture Department, University of Florida, Tropical Research and Education Center, 18905 SW 280th Street, Homestead, FL 33031-3314

Virginia S. Carvalho and José M.M. Dias

Departamento de Fitotecnia, Universidade Federal de Viçosa, Viçosa, MG, 36570-000, Brazil

\section{Ian Maguire}

Tropical Research and Education Center, University of Florida, 18905 SW 280th Street, Homestead, FL 33031-3314

Additional index words. liquid nitrogen, long-term storage, orchids, pollinia, vitrification, PVS2

\begin{abstract}
Pollination effectiveness was evaluated for pollen (pollinia) from two Dendrobium hybrids, 'Sena Red' and 'Mini WRL', submitted to cryopreservation using a vitrification protocol. Parameters evaluated included pollinia exposure to a previtrification solution (PVS2) under ice $\left(0^{\circ} \mathrm{C}\right)$ or room $\left(27 \pm 2{ }^{\circ} \mathrm{C}\right)$ temperatures from 1 to 4 hours before cryopreservation (LN). On removal from cryopreservation, pollinia were used to pollinate flowers of the same hybrids to verify viability and germination. All pollinia showed high percentages of germination (greater than $80 \%$ ) after crosses were performed, except for pollinia from Dendrobium 'Sena Red' submitted to 3 hours of precooling $\left(0^{\circ} \mathrm{C}\right)$ in $\mathrm{PVS} 2$ followed by $\mathrm{LN}(60 \%)$ and for pollinia submitted to $\mathrm{PVS} 2$ for 3 hours at room temperature with no precooling $(70 \%)$. Capsules were formed for both hybrids and seeds were successfully produced. The seed viability test revealed high viability $(90 \%$ to $95 \%)$ for all treatments for both hybrids. Seeds observed under a microscope contained well-formed embryos and no abnormalities were identified. Seeds from all treatments germinated. Germinating seeds developed into healthy seedlings with well-formed leaves and roots. Cryopreservation of pollinia was successfully accomplished either by direct storage in liquid nitrogen without cryoprotection treatments or by using a PVS2 vitrification protocol.
\end{abstract}

Orchid hybridization is a common and essential practice among orchid growers, and it is estimated that over 100,000 commercial hybrids have been developed worldwide at of the date of this writing aiming at the cut flower and flowering potted plant market. The main goal of hybridization in orchids is to generate new and improved material with characteristics of commercial interest such as new flower colors, color patterns, and flower size and number. By 2005, orchids ranked second place among potted floriculture crops in the United States with wholesale revenues estimated at \$144 million (U.S. Department of Agriculture, 2006). Today, orchid commercialization represents $8 \%$ of the global floriculture trade as a result of an increased demand (Martin and Madassery, 2006).

Received for publication 25 May 2007. Accepted for publication 13 Aug. 2007.

Funding for this project was provided by Coordenação de Aperfeiçoamento de Pessoal de Nível Superior (CAPES-Brasil) and by the University of Florida.

${ }^{1}$ To whom reprint requests should be addressed; e-mail vendrame@ufl.edu

from pollen grains (Pritchard and Prendergast, 1989).

Conventional pollen storage methods involving low temperature and low humidity have been developed for several species (Niimi and Shiokawa, 1992; Towill, 1985; Yates et al., 1991). Cryopreservation of pollen has also been applied to different species (Grout and Roberts, 1995) using different cryoprotectants (Liang et al., 1993; Parton et al., 2002; Pritchard and Prendergast, 1989; Tai and Miller, 2002; Towill, 1985). General orchid pollen storage techniques have also been described (Meeyot and Kamemoto, 1969; Seaton, 1994; Shijun, 1984); and cryopreservation has been reported in orchids for seeds, protocorms, zygotic embryos, pollinia, and cell suspensions (Hirano et al., 2005; Ishikawa et al., 1997; Ito, 1965; Popova et al., 2003; Pritchard, 1984; Pritchard et al., 1999; Thammasiri, 2000; Wang et al., 1998). Vitrification in particular has been used successfully to cryopreserve plant tissues and organs (Fahy et al., 1984; Sakai et al., 1990; Thammasiri, 2000); and it has been shown as a practical, quick, simple, and reliable approach for conservation of orchid seed accessions. However, no reports indicate the use of vitrification for cryopreservation of orchid pollen. Furthermore, most studies on cryopreservation of orchid pollen are limited to in vitro germination or pollen viability percentages after cryostorage with no further evaluation of pollen siring ability.

A protocol for cryopreservation of orchid pollen using vitrification was tested aiming to evaluate pollen viability by in situ germination through crosses, seed production, seed germination, and seedling growth and development after cryostorage.

\section{Materials and Methods}

Dendrobium hybrids are highly desirable as a result of the number of flowers per inflorescence and recurrent flowering characteristics (Martin and Madassery, 2006). Dendrobium hybrids also offer a large variety of flower colors and color patterns. Furthermore, their relatively short production cycle from seedling to a blooming plant provides a highly valuable and desirable characteristic for commercial large-scale production.

Pollen storage is of great importance for plant breeding and production as well as an efficient means for conservation of plant genetic resources and germplasm preservation of rare or endangered species (Connor and Towill, 1993; Grout and Roberts, 1995; Sacks and St. Clair, 1996). In orchids, pollen grains are fused into a structure called pollinium. The genus Dendrobium has pollen grains grouped into four pollinia (Sheehan and Sheehan, 1994).

Particularly for orchid breeding and production, the proper storage of pollen may allow crosses between plants that show temporal and spatial separation between periods of sexual reproduction. Orchid pollen storage may also be of use for the development of haploid plants through embryo development
Plant material. Pollinia were collected from two Dendrobium (Swartz.) hybrids, 'Sena Red' and 'Mini WRL', provided by Kerry's Bromeliads (Homestead, FL). All pollinia were collected in Dec. 2004, when flowers were completely open, and pollinia were stored in a desiccator containing silica gel for $24 \mathrm{~h}$. After desiccation, pollinia were immediately distributed among different treatments as described subsequently. In addition, three samples of four pollinia each, for each hybrid, were oven-dried at $103{ }^{\circ} \mathrm{C}$ for $17 \mathrm{~h}$ to constant weight, and the average initial pollen moisture content was determined before and after desiccation following standard procedures described by the International Seed Testing Association (International Seed Testing Association, 1993).

Vitrification procedure and treatments. Groups of four pollinia from the same flower were transferred to $2-\mathrm{mL}$ cryovials and $1 \mathrm{~mL}$ cryoprotective solution (2 $\mathrm{M}$ glycerol and $0.4 \mathrm{M}$ sucrose, $\mathrm{pH}$ 5.7) was added. Cryovials were left for $30 \mathrm{~min}$ at room temperature $\left(27 \pm 2{ }^{\circ} \mathrm{C}\right)$ before the addition of a plant vitrification solution. The plant vitrification solution, namely PVS2 (Sakai et al., 1990), consisted of $30 \%(\mathrm{w} / \mathrm{v})$ glycerol, $15 \%(\mathrm{w} / \mathrm{v})$ 
ethylene glycol, and 15\% (w/v) dimethyl sulfoxide (DMSO) in half-strength MS medium (Murashige and Skoog, 1962) supplemented with $0.4 \mathrm{M}$ sucrose (pH 5.7). The high concentration of PVS2 prevents ice crystallization during cryopreservation. Treatments consisted of pollinia left in PVS2 either at room temperature $\left(27 \pm 2{ }^{\circ} \mathrm{C}\right)$ or precooled in ice $\left(0{ }^{\circ} \mathrm{C}\right)$ for $1,2,3$, or $4 \mathrm{~h}$ before immersion in liquid nitrogen (LN) for 48 h. Four controls were established. Control 1 consisted of fresh pollinia collected from one flower and immediately used to pollinate another flower with no subsequent LN. Control 2 consisted of desiccated pollinia maintained in PVS2 for $2 \mathrm{~h}$ with no subsequent LN. Controls 3 and 4 consisted of desiccated pollinia placed directly into $\mathrm{LN}$ with or without the addition of PVS2, respectively. For control 2 (PVS2, no LN), pollinia were recovered and used to pollinate open flowers of plants from the same hybrids used in the experiment. Pollinated flowers in controls 1 and 2 were emasculated before pollination.

Pollen germination, seed germination, and seedling development. After $48 \mathrm{~h}$, controls under LN (3 and 4) and additional treatments were removed from $\mathrm{LN}$ and were rapidly thawed for $3 \mathrm{~min}$. The PVS2 solution was removed from each cryovial using a plastic, disposable transfer pipette. Approximately $1 \mathrm{~mL}$ of a $1.0 \mathrm{M}$ sucrose solution $(\mathrm{pH}$ 5.7) was added to each vial and held for $1 \mathrm{~h}$ at room temperature followed by two rinses in $1 \mathrm{~mL}$ deionized water for both controls 3 and 4 . The group of four pollinia from controls 3 and 4 and from each treatment were removed from cryovials and used to pollinate open flowers of plants from the same hybrids used in the experiment. All pollinated flowers were emasculated before pollination. Pollinated plants were maintained in a greenhouse for 6 months and pollen germination was evaluated by the success of the cross performed for each control or treatment. Cross success was evaluated by the formation of fruits (capsules) and viable seeds. Seed samples were removed from capsules of each control or treatment and seed viability was determined using two methods for consistency reasons, the 2,3,5-triphenyltetrazolium chloride (TTC) reduction assay (Singh, 1999) and also the fluorescein diacetate (FDA) staining technique (Pritchard, 1985). The TTC viability test consists of exposing seeds to $1 \%$ TTC (by volume) at $\mathrm{pH} 6.5$ for $24 \mathrm{~h}$ in dark at 27 to $30^{\circ} \mathrm{C}$. Viable embryos stain red. The FDA viability test consists of immersing orchid embryos in distilled water mixed 1:1 (by volume) on a microscope slide with a solution of FDA at $0.5 \%(\mathrm{w} / \mathrm{v})$ in absolute acetone. Viable embryos reveal a bright yellow fluorescent color under ultraviolet light. Seed samples were germinated in 1-L glass bottles containing half-strength MS medium (Murashige and Skoog, 1962) supplemented with $58.5 \mathrm{~mm}$ sucrose and solidified with $0.6 \%$ agar (Fisher, Chicago) and maintained at $27 \pm 2{ }^{\circ} \mathrm{C}, 60 \mu \mathrm{mol} \cdot \mathrm{m}^{-2} \cdot \mathrm{s}^{-1}$, 18/6 light/dark, $2 \times 9$ A Philips ${ }^{\circledR}$ fluorescent bulbs (Philips Lighting Co., Somerset, NJ).
Seed germination was evaluated for all treatments. Germinated seedlings were monitored weekly for shoot and root development and after 16 weeks, they were transplanted into either Magenta GA7 boxes (Sigma-Aldrich Co., St. Louis, MO) or Phytotech P700 culture boxes (Phytotechnology Laboratories, Shawnee Mission, KS) containing the same medium as described for germination. Seedlings were monitored for growth and development and were maintained at $27 \pm 2{ }^{\circ} \mathrm{C}$, $60 \mu \mathrm{mol} \cdot \mathrm{m}^{-2} \cdot \mathrm{s}^{-1}, 18 / 6$ light/dark, $2 \times 9$ A Philips fluorescent bulbs (Philips Lighting Co.).

Experimental design and data analysis. The experimental design consisted of a $4 \times 2$ factorial for vitrification and precooling treatments plus four controls with 10 replicates of four pollinia per cryovial. Each group of four pollinia originated from the same flower and was used to pollinate a new flower from a plant from the same hybrid. The experiment was replicated twice. Pollen germination data were subjected to analysis of variance. Pollen germination was calculated by the number of flowers that were successfully pollinated showing capsule and seed formation. Data for percent germination were normalized using arcsine transformation. Seed germination was also evaluated. Means were compared using Duncan's multiple range test at $\alpha=0.05$.

\section{Results}

Pollinia from both Dendrobium hybrids showed moisture content $\approx 8 \%$ before desiccation and 5\% after desiccation. Figure $1 \mathrm{~A}$ depicts pollinia from Dendrobium 'Mini WRL'. Regardless of the treatment, all pollinia showed high percentages of germination. Pollinia collected fresh and immediately used for direct pollination (control 1) showed $60 \%$ germination for Dendrobium 'Sena Red' and $80 \%$ for Dendrobium 'Mini WRL'. For pollinia submitted to PVS2 without LN (control 2), PVS2 and LN (control 3), and LN without PVS2 (control 4), germination percentages were high (greater than $80 \%$ ) for both hybrids.

The lowest germination percentages $(60 \%)$ were observed for pollinia from Dendrobium 'Sena Red' submitted to $3 \mathrm{~h}$ of precooling $\left(0^{\circ} \mathrm{C}\right)$ in PVS2, followed by $\mathrm{LN}$, and were similar to direct pollination for the same hybrid. The second lowest germination percentages $(70 \%)$ were observed for pollinia submitted to PVS2 for $3 \mathrm{~h}$ at room temperature (no precooling). For all remaining precooling and room temperature treatments for Dendrobium 'Sena Red', germination percentages were high (greater than $80 \%$ ) and no significant differences were observed $(\alpha=0.05)$.

For Dendrobium 'Mini WRL', germination percentages were high for all controls and treatments (greater than $80 \%$ ) and no significant differences were observed $(\alpha=$ $0.05)$. As a consequence of high germination percentages, successful capsule formation was observed for both hybrids (Fig. 1B). Seeds were successfully produced and showed high viability ( $90 \%$ to $95 \%$ ) through both the
TTC and FDA methods for all treatments and controls for both hybrids. Seeds observed under a microscope $(50 \times)$ contained wellformed embryos and no abnormalities were identified (Fig. 1C). Seeds from all controls and treatments showed high germination percentages (greater than 90\%). Germinating seeds showed enlargement, change to green color, and development into protocorms. Protocorms developed leaf primordia and rhizoids and successfully developed into seedlings (Fig. 1D). Seedlings were healthy and showed well-formed leaves and roots (Fig. 1E).

\section{Discussion}

Although it has been determined that less than $20 \%$ moisture content in pollen is necessary for successful cryopreservation, there are no studies indicating the minimum moisture content necessary for pollen to keep its viability (Connor and Towill, 1993). In this study, the low pollinia moisture content ( $5 \%$ to $8 \%$ ) for both Dendrobium hybrids was sufficient to maintain viability after cryopreservation. Orchids are considered recalcitrant species in which their seeds are sensitive to desiccation and therefore should have sensitive pollen as well (Towill, 2002). Meeyot and Kamemoto (1969) indicated that the use of silica gel reduced dramatically the pollen percent germination in different species and hybrids of Dendrobium after desiccation and subsequent storage at either 45 or $72{ }^{\circ} \mathrm{C}$. In contrast, Shijun (1984) indicated successful storage of air-dried pollen at 4 to $6^{\circ} \mathrm{C}$ for up to $280 \mathrm{~d}$ for species of Dendrobium, Vanda, Cymbidium, and Arachnis. However, in both studies, there was no indication as to the moisture content levels. Our results indicate that pollinia from the particular hybrids used in this study are tolerant to a silica gel desiccation treatment to $5 \%$ moisture content without subsequent negative effects on cryopreservation.

Pollinia from 'Sena Red' submitted to PVS2 or room temperature before LN showed higher germination percentages than pollinia immediately used for direct pollination. This enhanced germination of pollen after cryopreservation could be an effect of glycerol present in the PVS2 solution. Pritchard and Prendergast (1989) indicated that glycerol increases pollen tube lengths during in vitro germination after cryopreservation, suggesting it could be acting as a source of carbohydrate for heterotrophic pollen tube growth or wall formation. However, the suggested positive effect of glycerol is yet to be investigated.

The first report on low temperature storage of orchid pollen (Ito, 1965) indicated that pollen of Dendrobium nobile, Dendrobium 'Lady Hamilton', and Calanthe furcata germinated "well" after $957 \mathrm{~d}$ under $-79{ }^{\circ} \mathrm{C}$ using a cryoprotectant mixture of glycerol/ ethyl alcohol. However, percent germination was not indicated. In contrast, Pritchard and Prendergast (1989) indicated that cryoprotectants such as glycerol and DMSO reduced 

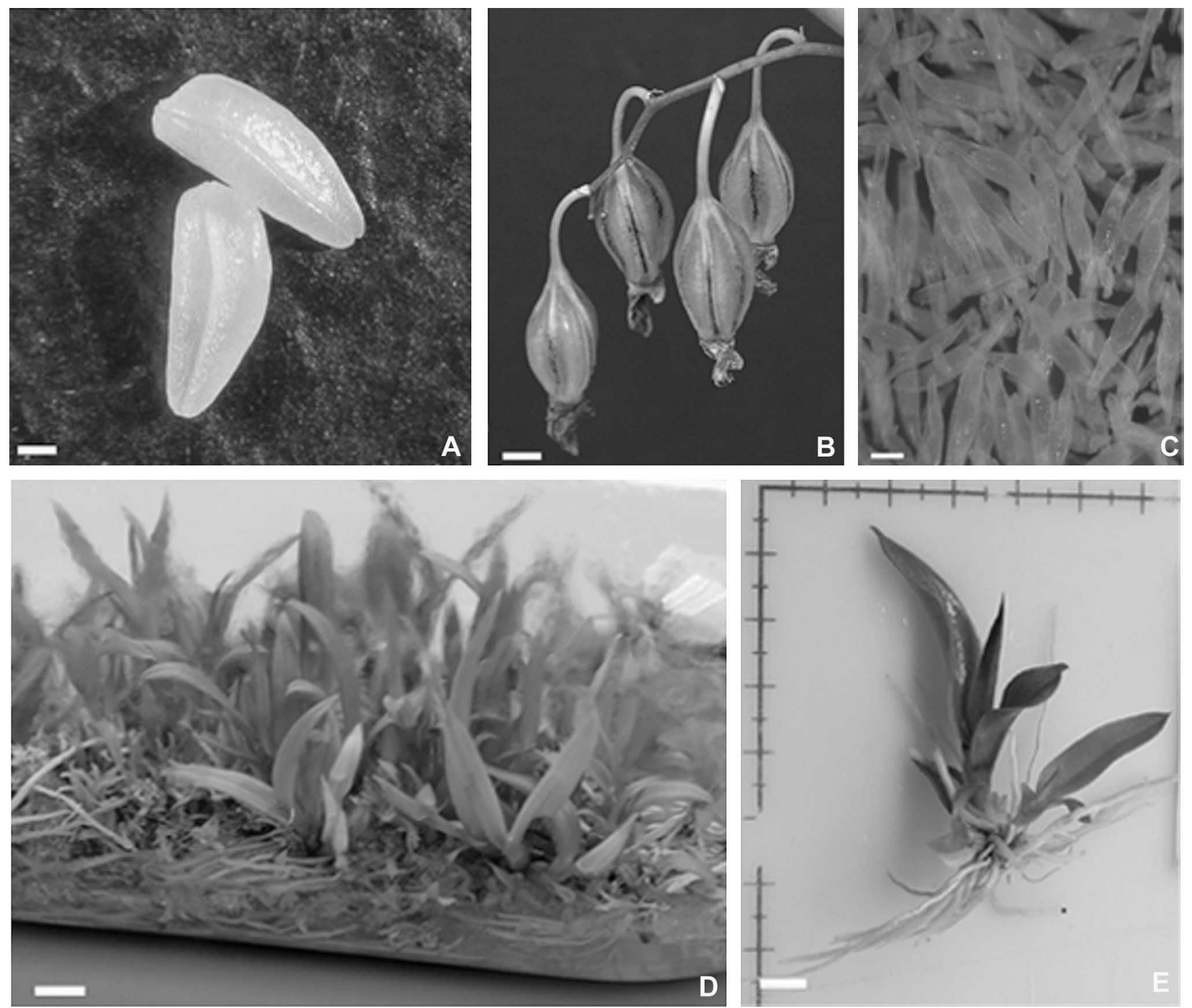

Fig. 1. (A) Pollinia removed from Dendrobium 'Mini WRL' flowers before cryopreservation. Bar $=0.3 \mathrm{~mm}$. (B) Capsules formed from crosses performed using cryopreserved pollinia. Bar $=0.5 \mathrm{~cm}$. (C) Seeds from Dendrobium 'Mini WRL' capsules. Bar $=0.15 \mathrm{~mm}$. (D) Developing seedlings 6 months after seed germination. Bar $=0.5 \mathrm{~cm}$. (E) Developing seedling showing healthy and normal shoot and root formation. $\mathrm{Bar}=0.5 \mathrm{~cm}$.

orchid pollen viability after cryopreservation $\left(196{ }^{\circ} \mathrm{C}\right)$ for several species, except for Dactylorhiza maculata and Listera ovata. Although these studies addressed ultralow temperature storage of pollen, no subsequent studies were performed on the pollen siring ability, fertilization, seed germination, and seedling development.

In our study, regardless of treatment, pollen germination percentage, as depicted by both capsule and subsequent seed formation, was high showing no effect of the vitrification procedure on enhancing cryopreservation of pollen for the hybrids tested. All capsules produced viable seeds, which germinated normally. Seed germination was observed for both hybrids at high percentages for all treatments, thus validating the results from the seed viability tests. Both the FDA and TTC tests returned similar results. The TTC method in particular has been shown as a feasible method for determination of orchid seed viability after cryopreservation (Hirano et al., 2005).

The determination of moisture content in tissues is essential for successful cryopreservation (Pence, 1992). Low moisture content of tissues allows proper and successful cryopreservation. Likewise, the use of proper cryoprotectants can increase the success of cryopreservation protocols. The PVS2 solution is highly concentrated and allows cooling to and warming from liquid nitrogen while suppressing ice crystallization (Sakai et al., 1990). In addition, any possible damage by chemical toxicity or osmotic stress is minimized (Sakai et al., 1990; 1991a, b). In this study, by reducing pollinia moisture content to $5 \%$ and exposing pollinia to PVS2 for a period of time, sufficient dehydration and cryoprotection for vitrification was expected on rapid cooling in LN. How- ever, the direct cryostorage of fresh pollinia was feasible without the need for any desiccation, cryoprotection, or precooling treatment before LN as demonstrated in our study. This is likely the result of the low initial moisture content $(8 \%)$ shown in the fresh pollinia for both hybrids.

The effects of the vitrification procedure on cryopreservation of orchid pollinia with higher moisture content still remains to be investigated. In this study, cryopreserved pollinia from both hybrids was recovered from LN and allowed successful crosses, generating viable seeds, which germinated and developed into healthy and normal seedlings. Pollinia from both Dendrobium hybrids at reduced moisture content $(5 \%$ to $8 \%$ ) were effectively cryopreserved either when submitted to a PVS2 vitrification protocol or when directly immersed in LN without cryoprotectants. 


\section{Literature Cited}

Connor, K.F. and L.E. Towill. 1993. Pollen-handling protocol and hydration/dehydration characteristics of pollen for application to longterm storage. Euphytica 68:77-84.

Fahy, G.M., D.R. MacFarlane, C.A. Angell, and H.T Meryman. 1984. Vitrification as an approach to cryopreservation. Cryobiology 21:407-426.

Grout, B.W.W. and A.V. Roberts. 1995. Storage of free pollen, pollen embryos and the zygotic embryos of seed by cryopreservation and freeze drying, p. 63-74. In: B.W.W. Grout (ed.). Genetic preservation of plant cells in vitro. Springer-Verlag, Berlin.

Hirano, T., T. Godo, M. Mii, and K. Ishikawa. 2005. Cryopreservation of immature seeds of Bletilla striata by vitrification. Plant Cell Rep. 23:534-539.

International Seed Testing Association. 1993. International rules for seed testing 1993. Seed Sci Technol. 21(Suppl.) 288 pp.

Ishikawa, K., K. Harata, M. Mii, A. Sakai, K. Yoshimatsu, and K. Shimomura. 1997. Cryopreservation of zygotic embryos of Japanese terrestrial orchid (Bletilla striata) by vitrification. Plant Cell Rep. 16:754-757.

Ito, I. 1965. Ultra-low temperature storage of pollinia and seeds of orchids. Jap. Orchid Soc. Bull. 11:4-15.

Liang, L., B.F. Xu, C.Y. Zheng, and C. Zhou. 1993. Pollen cryopreservation and pollen protoplast isolation in Brassica campestris var. purpurea. Acta Bot. Sin. 35:733-738.

Martin, K.P. and J. Madassery. 2006. Rapid in vitro propagation of Dendrobium hybrids through direct shoot formation from foliar explants, and protocorm-like bodies. Sci. Hort. 108:95-99.

Meeyot, W. and H. Kamemoto. 1969. Studies on storage of orchid pollen. Amer. Orchid Soc. Bull. 38:388-393.

Murashige, T. and F. Skoog. 1962. A revised medium for rapid growth and bioassays with tobacco tissue cultures. Physiol. Plant. 15:473-497.
Niimi, Y. and Y. Shiokawa. 1992. A study on the storage of Lilium pollen. J. Jpn. Soc. Hort. Sci. 61:393-403.

Parton, E., I. Vervaeke, R. Delen, R. Vandenbussche, R. Deroose, and M. De Proft. 2002. Viability and storage of bromeliad pollen. Euphytica 125:155-161.

Pence, V.C. 1992. Desiccation and the survival of Aesculus, Castanea, and Quercus embryo axes through cryopreservation. Cryobiology 29:391-399

Popova, E.V., T.V. Nikishina, G.L. Kolomeitseva, and A.S. Popov. 2003. The effect of seed cryopreservation on the development of protocorms by the hybrid orchid Bratonia. Russ. J. Plant Physiol. 50:672-677.

Pritchard, H.W. 1984. Liquid nitrogen preservation of terrestrial and epiphytic orchid seed. Cryo Letters 5:295-300.

Pritchard, H.W. 1985. Determination of orchid seed viability using fluorescein diacetate. Plant Cell Environ. 8:727-730.

Pritchard, H.W., A.L.C. Poynter, and P.T. Seaton. 1999. Interspecific variation in orchid seed longevity in relation to ultra-dry storage and cryopreservation. Lindleyana 14:92-101.

Pritchard, H.W. and F.G. Prendergast. 1989. Factors influencing the germination and storage characteristics of orchid pollen, p. 1-16. In: H.W. Pritchard (ed.). Modern methods in orchid conservation: The role of physiology, ecology and management. Cambridge University Press, Cambridge.

Sacks, E.J. and D.A. St Clair. 1996. Cryogenic storage of tomato pollen: Effect on fecundity. HortScience. 31:447-448.

Sakai, A., S. Kobayashi, and I. Oiyama. 1990. Cryopreservation of nucellar cells of navel orange (Citrus sinensis Osb.var. brasiliensis Tanaka) by vitrification. Plant Cell Rep. 9: 30-33.

Sakai, A., S. Kobayashi, and I. Oiyama. 1991a. Survival by vitrification of nucellar cells of navel orange (Citrus sinensis Osb.var. brasi- liensis Tanaka) cooled to $-196^{\circ} \mathrm{C}$. J. Plant Physiol. 137:465-470.

Sakai, A., S. Kobayashi, and I. Oiyama. 1991b. Cryopreservation of nucellar cells of navel orange (Citrus sinensis Osb.) by a simple freezing method. Plant Sci. 74:243-248.

Seaton, P. 1994. Orchid seed and pollen storage. Amer. Orchid Soc. Bull. 63:918-922.

Sheehan, T. and M. Sheehan. 1994. An illustrated survey of orchid. Genera, Timber Press, Portland, OR.

Shijun, C. 1984. The study of keeping freshness of orchid pollinia. Acta Hort Sin. 11:279-280.

Singh, F. 1999. Differential staining of orchid seeds for viability testing. Amer. Orchid Soc. Bull. 50:416-418.

Tai, P.Y.P. and J.D. Miller. 2002. In vivo viability assay of sugarcane pollen stored at ultra low temperature following preservation treatments, p. 5-9. Sugar Cane Int., January/Feb.

Thammasiri, K. 2000. Cryopreservation of seeds of a Thai orchid (Doritis pulcherrima Lindl.) by vitrification. Cryo Letters 21:237-244.

Towill, L.E. 1985. Low temperature and freezevacuum-drying preservation of pollen, p. 171198. In: K.K. Kartha (ed.). Cryopreservation of plant cells and organs. CRC Press, Boca Raton, FL.

Towill, L.E. 2002. Cryopreservation of plant germplasm: Introduction and some observations, p. 4-21. In: L.E. Towill and Y.P.S. Bajaj (eds.). Cryopreservation of plant germplasm II Springer-Verlag, Berlin.

U.S. Department of Agriculture. 2006. Floriculture crops-2005 summary. Natl. Agr. Stat. Serv., U.S. Dept. Agr., Washington, DC.

Wang, J.H., J.G. Ge, F. Liu, H.W. Bian, and C.N. Huang. 1998. Cryopreservation of seeds and protocorms of Dendrobium candidum. Cryo Letters 19:123-128.

Yates, I.E., D. Sparks, K. Connor, and L. Towill 1991. Reducing pollen moisture simplifies long-term storage of pecan pollen. J. Amer. Soc. Hort. Sci. 116:430-434 